\title{
Canadian Pain Society position statement on pain relief
}

\author{
Judith H Watt-Watson RN PhD ${ }^{1}$, A John Clark MD FRCPC ${ }^{2}$, G Allen Finley MD FRCPC ${ }^{3}$, C Peter N Watson MD FRCPC ${ }^{4}$
}

\section{JH Watt-Watson, AJ Clark, GA Finley, CPN Watson. Canadian Pain Society position statement on pain relief. Pain Res Manage 1999;4(2):75-78.}

The present report outlines key requirements that are central to helping patients manage pain effectively. Although current standards are available as guides for practice, the prevalence of pain suggests that many health professionals do not know and/or cannot relate to these standards. Therefore, a brief, pragmatic statement may be more useful initially for health professionals and patients learning about problematic pain outcomes. The principles in the brief statement produced by the Canadian Pain Society clarify and emphasize key underlying assumptions that have directed the development of many pain standards. The aim of the present paper is to increase awareness of ineffective pain practices and the importance of pain relief, and to stimulate further work in this area.

Key Words: Canadian Pain Society, Pain relief, Position statement

\section{Énoncé de position sur l'analgésie de la Société canadienne pour le traitement de la douleur}

RÉSUMÉ : Le présent rapport résume les critères de base mis de l'avant pour aider les patients à vaincre efficacement la douleur. Les normes actuelles servent peut-être de directives pratiques, mais la prévalence de la douleur donne à penser que de nombreux professionnels de la santé ne savent pas ou ne peuvent pas mettre ces normes en application. Par conséquent, un énoncé de position bref et concis pourrait être plus utile au départ pour mieux renseigner les professionnels de la santé et leurs patients au sujet de l'évolution parfois problématique de la douleur. Les principes de ce bref énoncé de la Société canadienne pour le traitement de la douleur clarifient les prémisses et soulignent les plus importantes, rappelant leur rôle dans la mise au point de nombreuses normes en matière d'analgésie. Le but du présent article est de sensibiliser davantage les médecins à l'inefficacité de certaines pratiques analgésiques et à l'importance de soulager la douleur et de promouvoir la recherche dans ce domaine.
$\mathrm{E}_{\mathrm{ft}}^{\mathrm{fi}}$ ffective pain management continues to be problematic in Canada as well as internationally. It is paradoxical that current treatment strategies can alleviate most pain, yet, over the past decade, many patients in a variety of settings have continued to report moderate to severe acute pain (1-10). Prescribed analgesic doses and intervals have been inadequate, analgesia has not been administered or analgesics have been administered in doses considerably less than those ordered (5,9,11-15). Although literature advocating changes in pain management practices has been available for at least a decade (16-18), inadequate pain relief outcomes continue to be reported.
Current standards or guidelines of pain management are often lengthy and based on the assumption that health professionals have the knowledge and commitment to apply them. Perhaps we have missed a step in our efforts to reduce pain management problems through published standards or guidelines. Health professionals may read standards but not understand the basis for their development and, hence, their relevance. Important principles that give direction to the development of standards need to be made explicit in clear and simple statements. This thinking prompted the Canadian Pain Society to appoint a committee to produce the position statement on pain relief. This statement was approved by the

\footnotetext{
${ }^{1}$ Faculty of Nursing, University of Toronto, Toronto, Ontario, ${ }^{2}$ Department of Anaesthesia, Dalhousie University, Pain Management Unit, Queen Elizabeth II Health Sciences Centre, Halifax, Nova Scotia, ${ }^{3}$ Departments of Anaesthesia \& Psychology, Dalhousie University, IWK Grace Health Centre, Halifax, Nova Scotia, ${ }^{4}$ Department of Medicine, University of Toronto, Etobicoke General Hospital, Toronto, Ontario

Correspondence and reprints: Dr Judith H Watt-Watson, Faculty of Nursing, University of Toronto, 50 St George Street, Toronto, Ontario M5S 3 H4. Telephone 416-978-2850, fax 416-978-8222, e-mail j.watt.watson@utoronto.ca
} 


\section{POSITION STATEMENT ON PAIN RELIEF}

Almost all acute and cancer pain can be relieved, and many patients with chronic nonmalignant pain can be helped. Patients have the right to the best pain relief possible.

\section{Unrelieved acute pain complicates recovery.}

Unrelieved pain after surgery or injury results in more complications, longer hospital stays, greater disability and potentially long-term pain.

\section{Routine assessment is essential for effective manage- ment.}

Pain is a subjective and highly variable experience. Therefore, patients' self-report of pain should be used whenever possible. For patients unable to report pain, a nonverbal assessment method must be used.

Health professionals have a responsibility to assess pain routinely, to believe patients' pain reports, to document pain reports, and to intervene in order to prevent pain.

3. The best pain management involves patients, families, and health professionals.

Patients and families must be informed that they have a right to the best pain relief possible and encouraged to communicate the severity of their pain.

Patients, families, and health professionals need to understand pain management strategies, including nonpharmacological techniques and the appropriate use of opioids.

Figure 1) Canadian Pain Society position statement on pain relief

Canadian Pain Society executive on December 13, 1997, as outlined in Figure 1 (19). Our purpose was to make explicit the key background assumptions that underlie the application of more detailed standards. Several issues were examined in the process with respect to the overall treatment of pain, including not only the use of opioids, but also additional aspects of pain relief.

\section{Current monitoring of pain practices}

Publicly displayed philosophies in health care organizations such as hospitals that often emphasize patient involvement in decision-making and staff accountability for quality care have not been applied to pain management practices. Documentation of pain assessment and the effectiveness of interventions such as opioids and using standardized scales has not been required, and chart audits have confirmed that this is rarely done (20). Only recently has the monitoring of pain management practices been included in accreditation standards. The revised standards from the Canadian Council on Health Facilities Accreditation (CCHFA) now include components requiring documentation of pain assessment and management, including patient response to treatment for pain (21). The accreditation evaluation also includes documentation of the interpersonal care process involved in symptom management. Recently, a large teaching hospital did not receive its usual, across-the-board, highest possible rating because of inadequate pain monitoring. Therefore, ongoing evaluation of pain management outcomes is not only ethical, but also pragmatic.

\section{Existing standards}

Standards guide practice and represent a degree of excellence established for a particular purpose, such as pain management (22). Standards are predetermined criteria to be used as a basis for comparison in providing guidance to health care facilities (23). Standards can be used by quality improvement committees in all facilities to monitor the contributions of health professionals to effective pain practices.

Useful standards for pain management already exist elsewhere. For example, in the United States, the Agency for Health Care Policy and Research (16) and the American Pain Society (APS) $(17,24)$ have been very influential in developing standards that are patient-focused and give clear direction for practice changes. The APS patient outcome measure reflects the standards and has recently been revised (17) to include components of the established Brief Pain Inventory (25) and the Barriers Questionnaire (26). The Canadian accreditation standards give clear direction to Canadian hospitals that ongoing assessment of the effectiveness of pain management is expected and a component of the CCHFA evaluation (21).

The APS and CCHFA standards have been developed thoughtfully and may already be in use by health professionals committed to pain relief. However, based on the lack of evidence of change, many health professionals do not seem to know about and/or cannot relate to these standards. Perhaps these individuals have no recent pain education and/or lack understanding about problematic pain outcomes. Perhaps the standards are considered too complex, unreadable or not relevant to practice.

While guidelines were available about specific pain strategies, such as opioid use for malignant and nonmalignant pain, it was felt that the issue required a broad, simple, pragmatic approach that would be easily remembered (27-32). Therefore, a brief position statement stating generic, key requirements for everyday practice was considered to be the most useful. The present paper is an interim step to facilitate implementation of the more comprehensive standards already available. The position statement on pain relief was presented as a work-in-progress for discussion and input at the Canadian Pain Society General Meeting in May 1997. The final version was approved in December 1997 and includes the following principles.

\section{Principle 1 - Unrelieved acute pain complicates recovery}

Unrelieved acute pain has consequences that can impede recovery for patients after surgery or trauma. Unrelieved pain can precipitate a generalized sympathetic response, which in- 
volves the pulmonary and cardiovascular systems $(33,34)$. For example, increases in heart rate, peripheral resistance, blood pressure and cardiac output can produce an increase in cardiac work and myocardial oxygen consumption. The diastolic filling time decreases with a greatly increased heart rate, which may cause an imbalance between myocardial oxygen demand and supply, and result in hypoxemia or ischemia. Pre-existing coronary artery disease may exacerbate this problem. As well, patients with greater pain after surgery have had a higher incidence of atelectasis (35). Fewer complications have been documented in surgical patients who reported effective pain relief after epidural infusions of analgesia and anesthesia than in patients receiving the traditional method of parenteral opioids as required (36).

The Agency for Health Policy and Research has emphasized the importance of effectively managing acute pain in order to meet the current requirements for earlier patient mobilization, reduced hospital stays and reduced costs (16). Patients who reported good pain relief with epidural analgesia and anesthesia following major peripheral vascular surgery had shorter intensive care unit stays $(1.5 \pm 1.4$ days versus $3.3 \pm 6.9, \mathrm{P}=0.03$ ) as well as fewer complications, including cardiovascular difficulties (four versus $11, \mathrm{P}=0.05$ ), deep vein thrombosis (one versus nine, $\mathrm{P}=0.007$ ) and infections (two versus eight, $\mathrm{P}=0.04$ ) (36). Similarly, Wasylak et al (37) reported that 38 women who used patient-controlled morphine for $48 \mathrm{~h}$ after a hysterectomy versus a control group (PRN morphine) were discharged earlier (75\% versus 56\% by day $6, \mathrm{P}<0.05$ ), had fewer infections ( $5 \%$ versus $39 \%$ received antibiotics, $\mathrm{P}=0.01$ ) and reported less disability (pain with activities, $\mathrm{P}<0.052$ ) two weeks after discharge. Most important is the research evidence that suggests that early treatment to relieve or minimize acute pain may prevent ensuing long-term pain (38-40). Early postoperative pain for thoracotomy patients was the only factor that significantly predicted pain 18 months after surgery (40).

\section{Principle 2 - Routine assessment is essential for effective management}

The personal nature and consequent variability of pain are emphasized in the Gate Control Theory $(41,42)$. Because pain perception and response are very individual, patients who are able to describe their pain must be asked about their pain experience. However, previous findings that patients do not remember being asked about their pain are problematic

\section{REFERENCES}

1. Abbott FV, Gray-Donald K, Sewitch MJ, Johnston CC, Edgar L, Jeans ME. The prevalence of pain in hospitalized patients and resolution over six months. Pain 1992;50:15-28.

2. Bookbinder M, Coyle N, Kiss M, et al. Implementing national standards for cancer pain management: program model and evaluation. J Pain Symptom Manage 1996;12:334-47.

3. Carr EC. Postoperative pain: patients' expectations and experiences. J Adv Nurs 1990;15:89-100.

4. Francke AL, Theeuwen I. Inhibition in expressing pain. A qualitative
$(10,43)$. Chart audits have confirmed that documentation of pain assessment and the effectiveness of interventions is rarely done. The inclusion of pain documentation in the new accreditation guidelines emphasizes the importance of individualized pain treatment assessments and evaluation of strategies.

Pain assessment with adults, infants and children who are unable to verbalize their pain experience is a challenge. It is hoped that, the assumption that pain does not exist when patients are nonverbal is disappearing. Considerable effort in this regard has been made by Canadian pain experts who are internationally recognized for their work in developing pain measures, particularly for infants and children (44-50).

\section{Principle 3 - The best pain management involves patients, families, and health professionals}

Patients' satisfaction ratings are sometimes used to monitor and evaluate their pain management; however, this outcome measure may be problematic because patients have not expected to have their pain relieved (51-53). Moreover, patients evaluate their pain management as satisfactory, in spite of reporting moderate to severe pain $(5,7,8)$. Furthermore, patients frequently are not given any information on which to base these evaluations. As a result, the standard that patients use for comparison may be their previous experiences and current expectations of severe pain. Therefore, patients and families must be informed that they have a right to the best pain relief possible and be encouraged to communicate the severity of their pain.

Ward et al (26) report a large number of patients who have concerns about using analgesics, including the fear of addiction. Although patients have stated that they would like total pain relief or as much relief as possible $(3,6,51,54)$, many wait until their pain is severe before asking for help or wait for the nurse to ask them about pain $(3,6,52)$. Therefore, patient education explaining pain relief strategies and the importance of effective pain management needs to become a priority.

Key requirements that are central to helping patients manage their pain effectively have been outlined in the position statement. These principles clarify and/or emphasize the underlying assumptions that have directed the development of many pain standards. The aim of the present paper is to increase awareness of ineffective pain practice and the importance of pain relief, and to stimulate further research in this area.

study among Dutch surgical breast cancer patients. Cancer Nurs 1994;17:193-9.

5. Miaskowski C, Nichols R, Brody R, Synold T. Assessment of patient satisfaction utilizing the American Pain Society's Quality Assurance Standards on acute and cancer-related pain. J Pain Symptom Manage 1994;9:5-11.

6. Owen H, McMillan V, Rogowski D. Postoperative pain therapy: a survey of patient's expectations and their experiences. Pain 1990;41:303-7. 
7. Ward SE, Gordon D. Application of the American Pain Society quality assurance standards. Pain 1994;56:266-306.

8. Ward SE, Gordon DB. Patient satisfaction and pain severity as outcomes in pain management: a longitudinal view of one setting's experience. J Pain Symptom Manage 1996;11:242-51.

9. Watt-Watson J, Graydon J. Impact of surgery on head and neck cancer patients and their caregivers. Nurs Clin North Am 1995;30:659-71.

10. Watt-Watson J, Garfinkel P, Gallop R, Stevens B, Streiner D. The impact of nurses' empathic responses on patients' pain management in acute care. Nursing Research. (In press)

11. Closs SJ. An exploratory analysis of nurses' provision of postoperative analgesic drugs. J Adv Nurs 1990;15:42-9.

12. Finley GA, McGrath PJ, Forward SP, McNeill G, Fitzgerald P. Parents' management of children's pain following 'minor' surgery. Pain 1996;64:83-7.

13. Maxam-Moore VA, Wilkie DJ, Woods SL. Analgesics for cardiac surgery patients in critical care: describing current practice. Am J Crit Care 1994;3:31-9.

14. Paice JA, Mahon SM, Faut-Callahan M. Factors associated with adequate pain control in hospitalized postsurgical patients diagnosed with cancer. Cancer Nurs 1991;14:298-305.

15. Watt-Watson J, Garfinkel P, Stevens B, Gallop R, Streiner D. Patients' perceptions of their pain experience after coronary bypass graft surgery. American Pain Society Book of Abstracts. November 14 to 17, 1996. (Abst 747)

16. Agency for Health Care Policy and Research (AHCPR). Acute pain management in infants, children, and adolescents: Operative and medical procedures (AHCPR Pub No 92-0020). Acute pain management: Operative or medical procedures and Trauma (Pub No 92-0032), 1992. Management of Cancer Pain (Pub No 94-0592). Quick reference guide for clinicians. Rockville: Public Health Service, United States Department of Health and Human Services, 1994.

17. American Pain Society Quality of Care Committee. Quality improvement guidelines for the treatment of acute pain and cancer pain. JAMA 1995;274:1874-80.

18. World Health Organization (WHO). Symptom Relief in Terminal Illness. Geneva: WHO, 1998.

19. Position statement on pain relief. Canadian Pain Society Newsletter. February, 1998.

20. Dalton JA, Blau W, Carlson J, et al. Changing the relationship among nurses' knowledge, self-reported behaviour, and documented behaviour in pain management: does education make a difference? J Pain Symptom Manage 1996;12:308-19.

21. Canadian Council on Health Facilities Accreditation (CCHFA), Standards for acute care organizations. Ottawa, 1995.

22. Sykes J, ed. The Concise Oxford Dictionary. St Louis: Clarendon Press, 1986.

23. Anderson K, Anderson L, Glanze W. Mosby's Medical, Nursing, and Allied Dictionary, 4th edn. Chicago: Mosby, 1994.

24. Max M. American Pain Society quality assurance standards for relief of acute and cancer pain. In: Bond MR, Charlton JE, Woolf CJ, eds. Proceedings of the VIth World Congress on Pain. New York: Elsevier Publishers, 1991:185-9.

25. Daut RL, Cleeland CS, Flanery RC. Development of the Wisconsin Brief Pain Questionnaire to assess pain in cancer and other diseases. Pain 1983;17:197-210.

26. Ward SE, Goldberg N, Miller-McCauley V, et al. Patient-related barriers to management of cancer pain. Pain 1993;52:319-24.

27. American Pain Society (APS). Principles of analgesic use in the treatment of acute pain and cancer pain, 3rd edn. Skokie: American Pain Society, 1992.

28. Goldman B, Gale G, Gilchrist G, Jacobs H, Kerr I, Rothbart P. Use of opioids for the treatment of chronic pain of nonmalignant origin. Pain Res Manage 1997;2:231-35.

29. Hagen N, Flynne P, Hays H, MacDonald N. Guidelines for managing chronic non-malignant pain. Opioids and other agents. Can Fam Physician 1995;41:49-53.

30. Moulin D. Opioid analgesics for chronic nonmalignant pain. Can J CME, 1996;8:137-144.

31. Portenoy RK. Opioid therapy for chronic nonmalignant pain. Pain Res Manage 1996;1:17-28.

32. Canadian Pain Society (CPS). Use of opioid analgesics for the treatment of chronic noncancer pain - A consensus statement and guidelines from the Canadian Pain Society. Pain Res Manage 1998;3:197-208.

33. Cousins M. Acute and postoperative pain. In: Wall P, Melzack R, eds. Textbook of Pain, 3rd edn. New York: Churchill Livingstone, 1994.

34. Yeager MP, Glass DD, Neff RK, Brinck-Johnsen T. Epidural anesthesia and analgesia in high-risk surgical patients. Anesthesthesiology 1987;66:729-36.

35. Puntillo K, Weiss SJ. Pain: its mediators and associated morbidity in critically ill cardiovascular surgical patients. Nurs Res 1994;43:31-6.

36. Tuman KJ, McCarthy RJ, March RJ, DeLaria GA, Patel RV, Ivankovich AD. Effects of epidural anesthesia and analgesia on coagulation and outcome after major vascular surgery. Anesth Analg 1991;73:696-704.

37. Wasylak TJ, Abbott FV, English MJ, Jeans ME. Reduction of postoperative morbidity following patient-controlled morphine. Can J Anaesth 1990;37:726-31.

38. Dworkin R. Acute herpes zoster and postherpetic neuralgia. Meeting of the 8th World Congress on Pain. Vancouver, August 17 to 22, 1996.

39. Kalso E. Prevention of chronicity. In: Jensen T, Turner J, Wiesenfeld-Hallin Z, eds. Proceedings of the 8th World Congress on Pain. Seattle: IASP Press, 1997:215-30.

40. Katz J. Perioperative predictors of long-term pain following surgery. In: Jensen T, Turner J, Wiesenfeld-Hallin Z, eds. Proceedings of the 8th World Congress on Pain. Seattle: IASP Press, 1997:231-42.

41. Melzack R, Wall PD. Pain mechanisms: a new theory. Science 1965;150:971-9.

42. Melzack R, Wall P. The Challenge of Pain. New York: Penguin, 1996.

43. Donovan M, Dillon P, McGuire L. Incidence and characteristics of pain in a sample of medical-surgical inpatients. Pain 1987;30:69-78

44. Chambers CT, Reid GJ, McGrath PJ, Finley GA. Development and preliminary validation of a postoperative pain measure for parents. Pain 1996;68:307-13.

45. Craig KD, Whitfield MF, Grunau RV, Linton J, Hadjistavropoulos HD. Pain in the preterm neonate: behavioral and physiological indices. Pain 1993;52:287-99.

46. Grunau R, Craig KD. Facial activity as a measure of neonatal pain expression. In: Tyler DC, Krane EJ, eds. Advances in Pain Research and Therapy. New York: Raven Press, 1990:147-56.

47. McGrath PA, Seifert CE, Speechley KN, Booth JC, Stitt L, Gibson MC. A new analogue scale for assessing children's pain: an intitial validation study. Pain 1996;64:435-43.

48. McGrath PJ. Behavioural measures of pain. In: Finley GA, McGrath PJ, eds. Measurement of Pain in Infants and Children. Seattle: IASP Press, 1998:83-102.

49. Stevens BJ, Johnston CC, Horton L. Factors that influence the behavioural pain responses of infants. Pain 1994;59:101-9.

50. Stevens B, Johnston C, Petryshen P, Taddio A. Premature Infant Pain Profile: development and initial validation. Clin J Pain 1996;12:13-22.

51. Cohen F. Postsurgical pain relief: Patients' status and nurses' medication choices. Pain 1990;9:265-74.

52. Lavies N, Hart L, Rounsefell B, Runciman W. Identification of patient, medical and nursing staff attitudes to postoperative opioid analgesia: stage 1 of a longitudinal study of postoperative analgesia. Pain 1992;48:313-9.

53. Weis OF, Sriwatanakul K, Alloza JL, Weintraub M, Lasagna L. Attitudes of patients, housestaff, and nurses toward postoperative analgesic care. Anaesth Analg 1983;62:70-4.

54. Kuhn S, Cooke K, Collins M, Jones JM, Mucklow JC. Perceptions of pain relief after surgery. BMJ 1990;300:1687-90. 


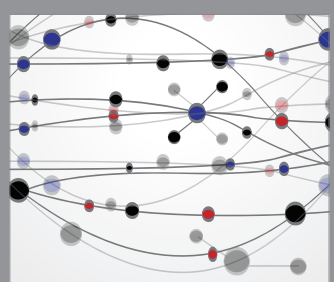

The Scientific World Journal
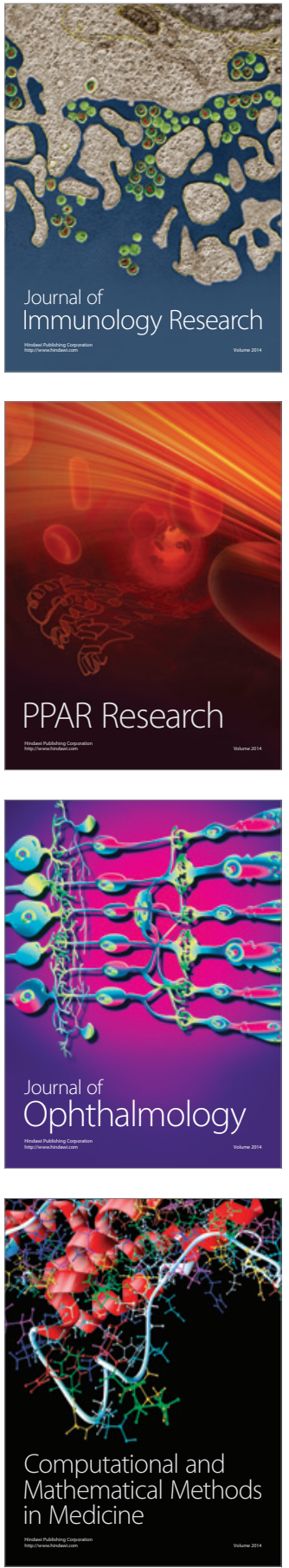

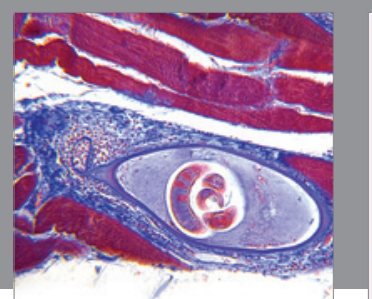

Gastroenterology Research and Practice

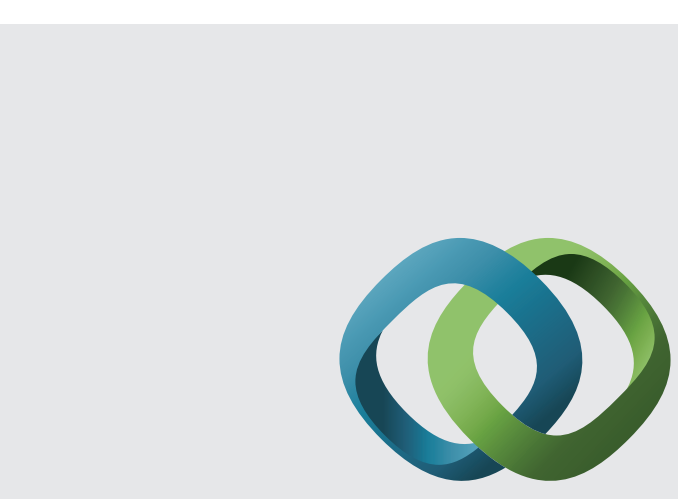

\section{Hindawi}

Submit your manuscripts at

http://www.hindawi.com
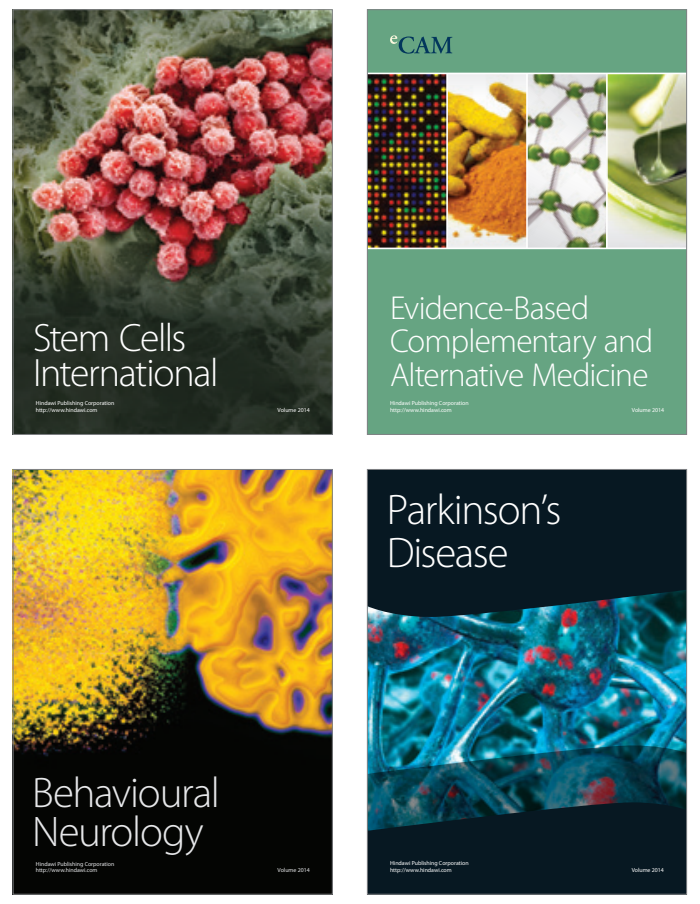
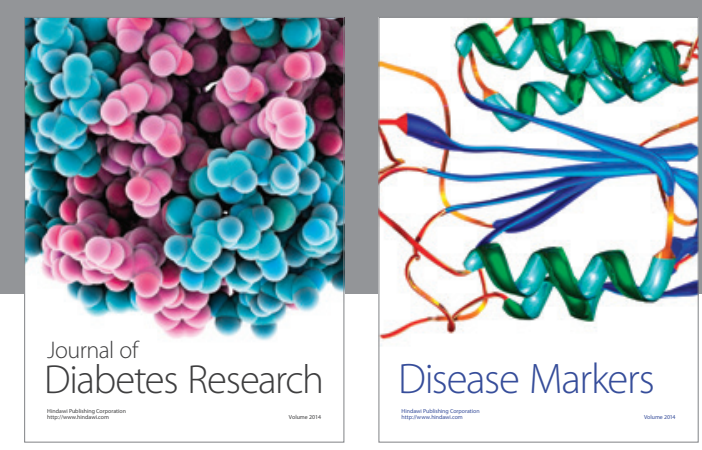

Disease Markers
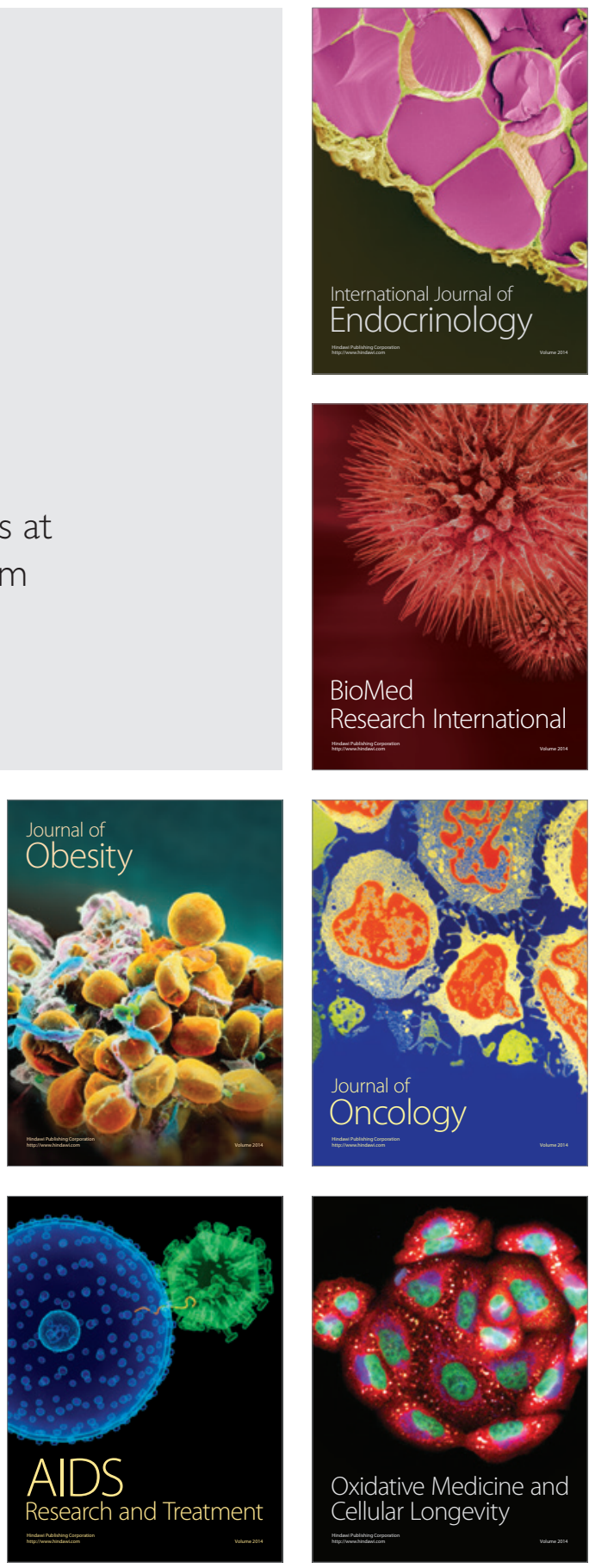